\title{
Neuropathic pain responds better to increased doses of pregabalin: an in-depth analysis of flexible-dose clinical trials
}

This article was published in the following Dove Press journal:

Journal of Pain Research

26 July 2017

Number of times this article has been viewed

\author{
Michael Serpell' \\ Mark Latymer ${ }^{2}$ \\ Mary Almas ${ }^{3}$ \\ Marie Ortiz ${ }^{4}$ \\ Bruce Parsons ${ }^{4}$ \\ Rita Prieto 5 \\ 'University Department of \\ Anaesthesia, Stobhill Ambulatory \\ Care Hospital, Glasgow, ${ }^{2}$ Pfizer Ltd, \\ Tadworth, UK; ${ }^{3}$ Pfizer, Groton, CT, \\ ${ }^{4}$ Pfizer, New York, NY, USA; ${ }^{5}$ Pfizer \\ GEP SLU, Madrid, Spain
}

Background: Pregabalin is an effective treatment option for many patients with neuropathic pain. Higher doses of pregabalin have been shown to be more effective in improving pain outcomes but, in practice, failing to appropriately increase the dose can leave patients under-treated. Methods: This was a pooled analysis of 6 flexible-dose clinical trials of pregabalin in patients with neuropathic pain (diabetic peripheral neuropathy, peripheral herpetic neuralgia, posttraumatic pain, or postsurgical pain). Patients were divided into "dose pathway" groups based on their weekly pregabalin dose from the start of their trial to the first week of their maintenance phase. These were: $150 \mathrm{mg}$ /day only; 150 to $300 \mathrm{mg} /$ day; 150 to 300 to $450 \mathrm{mg} / \mathrm{day} ; 150$ to 300 to 450 to $600 \mathrm{mg} /$ day; 150 to 300 to $600 \mathrm{mg} /$ day; 300 to $600 \mathrm{mg} /$ day. Pain outcomes assessed for each group at each new dose were proportion of $30 \%$ and $50 \%$ responders ( $\geq 30 \%$ or $\geq 50 \%$ reduction in mean pain score from baseline) and mean change in pain score. Percent change in mean pain score from baseline was assessed using a marginal structural model.

Results: Seven hundred and sixty-one patients treated with flexible-dose pregabalin were included in the analysis. For each dose pathway group, there was a notably greater proportion of $30 \%$ and $50 \%$ responders and change in pain score, at each escalating dose. As assessed by the marginal structural model, higher doses of pregabalin were estimated to result in a significantly greater change in mean pain score at each week. This dose response with flexible-dose pregabalin was consistent with that previously observed with fixed-dose pregabalin.

Conclusion: Many patients who do not respond to lower doses of pregabalin will respond with notable improvements in pain outcomes when the dose is escalated. These data should encourage physicians treating patients with neuropathic pain to escalate pregabalin to the dose that delivers optimal analgesia and tolerable side effects.

Keywords: neuropathic pain, pregabalin, dosing

\section{Introduction}

Neuropathic pain, defined as "pain arising as a direct consequence of a lesion or disease affecting the somatosensory system"1 is a common chronic pain condition. The condition represents a significant burden on patients and healthcare systems, and can be challenging to diagnose and effectively treat. ${ }^{2,3}$ Despite the availability of a number of effective pharmacological treatment options, ${ }^{4}$ many patients with neuropathic pain, particularly those with more severe conditions, may be untreated or undertreated. ${ }^{5}$

Pregabalin (Pfizer, New York, USA), an $\alpha_{2} \delta$ ligand, is indicated in the USA for the treatment of diabetic peripheral neuropathy (DPN), peripheral herpetic neuralgia (PHN), and spinal cord injury, ${ }^{6}$ and in Europe for the treatment of peripheral and central neuropathic pain. ${ }^{7}$ It is recommended as a first-line treatment for diverse neu-
Correspondence: Michael Serpell University Department of Anaesthesia, Pain Office, 3rd Floor, Stobhill Ambulatory Care Hospital, I33 Balornock Road, Glasgow G2I 3UW, UK Tel +44 I4I 355 I490

Email mgserpell@cheerful.com 
ropathic pain conditions (including DPN, PHN, and central pain) by the European Federation of Neurological Societies, ${ }^{4}$ the International Association for the Study of Pain, ${ }^{8}$ and the American Academy of Neurology. ${ }^{9}, 10$ While pregabalin is not effective in every patient with neuropathic pain, its efficacy has been demonstrated in clinical trials and meta-analyses. ${ }^{11}$ Cumulatively, it is estimated that there have now been over 34 million patient-years of exposure to pregabalin. ${ }^{12}$

A meta-analysis of clinical trials of different treatments for the neuropathic pain condition DPN concluded that pregabalin at doses $\geq 300 \mathrm{mg}$ /day was more effective in improving pain than pregabalin at doses $\leq 150 \mathrm{mg} /$ day; ${ }^{13}$ although many patients do respond to treatment with pregabalin at lower doses ( $\leq 300 \mathrm{mg} /$ day). ${ }^{13,14}$ As a consequence, it is recommended that in clinical practice, pregabalin should be carefully escalated to the dose that delivers optimal analgesia and tolerable side effects. ${ }^{4,6,15}$ Despite this, some physicians may not attempt a higher dose of pregabalin in patients who do not respond at an initial low dose and many patients receive doses $\leq 150 \mathrm{mg} /$ day. ${ }^{16}$

New evidence showing that there are patients who do not respond to a low dose of pregabalin but who do subsequently respond when the dose is increased may help to provide clearer guidance to physicians and more effective treatment to patients. This analysis pooled individual patient-level data from 6 randomized, placebo-controlled studies of flexibledose pregabalin in neuropathic pain with the aim of assessing how patients who do not initially respond to pregabalin at lower doses react to increasing doses.

\section{Methods \\ Source data}

This analysis included all Pfizer-sponsored studies of pregabalin completed at the time the analysis started that met the following criteria: randomized, parallel, placebo-controlled; conducted in patients with neuropathic pain; and included a treatment arm of flexible-dose pregabalin (150 to 600 $\mathrm{mg} /$ day). Only Pfizer-sponsored studies were included as patient-level data were required for the analysis. A total of 6 trials met these criteria. A 12-week trial conducted in 406 patients with DPN, A0081030 (ClinicalTrials.gov: NCT00156078). ${ }^{17}$ A 4-week trial conducted in 269 patients with PHN, A0081004 (NCT00159666). ${ }^{18}$ A 12-week trial conducted in 338 patients with either DPN or PHN, 10081155. ${ }^{19}$ An 8-week trial conducted in 308 patients with either DPN or PHN, A0081081 (NCT00301223). ${ }^{20}$ An 8-week trial conducted in 254 patients with posttraumatic or postsurgical (PT/PS) pain, A0081064 (NCT00292188). ${ }^{21}$ An 8-week trial conducted in 240 patients with DPN, PHN, or PT/PS,
A0081037 (NCT00141219). ${ }^{22}$ Some historical trials are not recorded at ClinicalTrials.gov.

The trials were conducted between July 2001 and May 2008 and included patients from Asia, Europe, the Middle East, and North and South America. The primary efficacy outcome in each study was the change in mean pain score at endpoint compared with placebo. Mean pain score was the mean score over the past 7 days as recorded by patients in a daily pain diary and measured using an 11-point numeric rating scale scored from 0 (no pain) to 10 (worst possible pain).

Data on the pain response to fixed-dose pregabalin were taken from all Pfizer-sponsored, randomized, placebo-controlled trials of pregabalin in patients with neuropathic pain. This was a total of 27 trials: $1008-1014,{ }^{23}$ $1008-1029,{ }^{24} 1008-1030,{ }^{25} 1008-1040,{ }^{25} 1008-1045,{ }^{26}$ $1008-1125,{ }^{27} 1008-1127,{ }^{28} 1008-1131,{ }^{29} 1008-1149,{ }^{30}$ 1008-1155, ${ }^{19}$ 1008-1196, ${ }^{31}$ A0081004 (ClinicalTrials. gov: NCT00159666), ${ }^{18}$ A0081030 (NCT00156078), ${ }^{17}$ A0081037 (NCT00141219), ${ }^{22}$ A0081060 (NCT00159679), ${ }^{32}$ A0081064 (NCT00292188), ${ }^{21}$ A0081066, ${ }^{33}$ A0081071 (NCT00143156), ${ }^{17} \mathrm{~A} 0081081$ (NCT00301223), ${ }^{20} \mathrm{~A} 0081107$ (NCT00407745), ${ }^{34} \mathrm{~A} 0081120$ (NCT00394901), ${ }^{35} \mathrm{~A} 0081163$ (NCT00553475), ${ }^{36} \mathrm{~A} 0081244$ (NCT01049217), ${ }^{37} \mathrm{~A} 0081265$ (NCT01332149), A0081268 (NCT01455415), ${ }^{38}$ A0081269 (NCT01474772), ${ }^{39}$ and A0081276 (NCT01455428). ${ }^{40}$ Some historical trials are not recorded at ClinicalTrials.gov.

The protocol for each trial adhered to the International Ethical Guidelines for Biomedical Research Involving Human Subjects, the International Conference on Harmonisation Good Clinical Practice guidelines, and the Helsinki Declaration. All trials were approved by the appropriate independent ethics committee and all patients provided written informed consent.

\section{Dose pathway groups}

To be included in this analysis, patients had to have $\geq 80 \%$ compliance on the study drug (calculated by total number of days on a valid dose/duration of treatment), to have remained in their study for at least 28 days, and to have been receiving a stable dose of pregabalin for at least 4 days. Patients were grouped into dose pathways based on the pattern of their pregabalin dose at each week during titration phase and up to 1 week of their maintenance phase. The dose pathway groups were: $150 \mathrm{mg} /$ day only; 150 to $300 \mathrm{mg} /$ day; 150 to 300 to $450 \mathrm{mg} /$ day; 150 to 300 to 450 to $600 \mathrm{mg} /$ day; 150 to 300 to $600 \mathrm{mg} / \mathrm{day}$; and 300 to $600 \mathrm{mg} /$ day. Each patient was included in a single-dose pathway group. Patients who decreased their dose at any visit or who did not remain at the particular dose level for at least 4 days were not included in a dose pathway group. 


\section{Statistical analysis}

Descriptive statistics were used to describe outcomes in treatment-compliant and non-compliant patients for each dose pathway. Assessed outcomes included: proportion of $30 \%$ responders (patients with $\geq 30 \%$ reduction in mean pain score from baseline); proportion of 50\% responders (patients with $\geq 50 \%$ reduction in mean pain score from baseline); and mean change in pain score at each new dose. $\mathrm{A} \geq 30 \%$ reduction in mean pain score from baseline, or a 2-point change in pain score, was accepted to represent a clinically important difference. ${ }^{41,42}$ For the descriptive analysis, patients were also required to have had $\geq 80 \%$ compliance on pregabalin over the entire study.

In addition, the percent change in mean pain score from baseline was assessed using a marginal structural model (MSM) ${ }^{43,44}$ A MSM was selected for this analysis as it can accommodate both multiple time-independent covariates, such as baseline clinical and demographic variables and time-dependent covariates, such as treatment and treatment outcomes, even in the presence of missing data and timevarying confounders, as is the case in flexible-dose studies. Specifically, the MSM was a weighted repeated-measures approach using treatment as a time-varying covariate in which weights, based on inverse probability of treatment weighting, control for time-dependent confounders. This produced a pseudo-population with balance in both time-invariant and time-varying covariates that allowed for causal treatment comparisons using standard repeated-measure models. The weighting could also be adjusted to incorporate adjustments for missing data that provides validity under missing at random. Patients were included in the MSM analysis regardless of their level of treatment compliance but a separate analysis limited to patients with $\geq 80 \%$ compliance on pregabalin was conducted for comparison. As a sensitivity analysis, an unweighted estimate of the change in mean pain score from baseline was also conducted. The MSM-estimated change with flexible-dose pregabalin conducted in this analysis was also compared directly with the estimated change in mean pain score from baseline with fixed-dose pregabalin. The study conducted in PHN patients alone, A0081004 (NCT00159666), ${ }^{18}$ was included in the descriptive analysis but not in the MSMestimated models as the length of the study was only 4 weeks (compared with 8 or 12 weeks for all other studies).

\section{Results}

\section{Patient population}

A total of 889 patients were treated with flexible-dose pregabalin; 761 of which met the inclusion criteria $(\geq 80 \%$ compliance on pregabalin, had remained in their study for $\geq 28$ days, and receiving a stable dose of pregabalin for $\geq 4$ days) and were included in the descriptive analysis. Of these, 717 could be grouped into one of the six established dose response pathways. The demographic characteristics and baseline clinical characteristics of patients were broadly similar regardless of treatment compliance (Table 1).

\section{Improvement in pain outcomes in each dose pathway}

Cumulative assessment of the proportion of $30 \%$ (Figure 1) and $50 \%$ (Figure 2) pain responders for each dose pathway

Table I Baseline demographic and clinical characteristics

\begin{tabular}{|c|c|c|}
\hline Characteristic & $\begin{array}{l}\text { Pregabalin } \\
\text { (all patients) }\end{array}$ & $\begin{array}{l}\text { Pregabalin } \\
\text { ( } \geq 80 \% \text { compliant) }\end{array}$ \\
\hline $\mathrm{N}$ & 889 & 761 \\
\hline Female, n (\%) & $489(55.0)$ & $4 \mid 3(54.3)$ \\
\hline Male, n (\%) & $400(45.0)$ & $348(45.7)$ \\
\hline \multicolumn{3}{|l|}{ Race, n (\%) } \\
\hline White & $327(36.9)$ & $264(34.7)$ \\
\hline Asian & $503(56.6)$ & $444(58.3)$ \\
\hline Black & $9(1.0)$ & $8(I .1)$ \\
\hline Other & $50(5.6)$ & $45(5.9)$ \\
\hline \multicolumn{3}{|l|}{ Age, years } \\
\hline Mean (SD) & $58.5(11.0)$ & $58.8(10.5)$ \\
\hline Median & 59.0 & 60.0 \\
\hline \multicolumn{3}{|c|}{ Baseline pain score } \\
\hline Mean (SD) & $6.4(1.6)$ & $6.3(1.6)$ \\
\hline Median & 6.3 & 6.3 \\
\hline
\end{tabular}

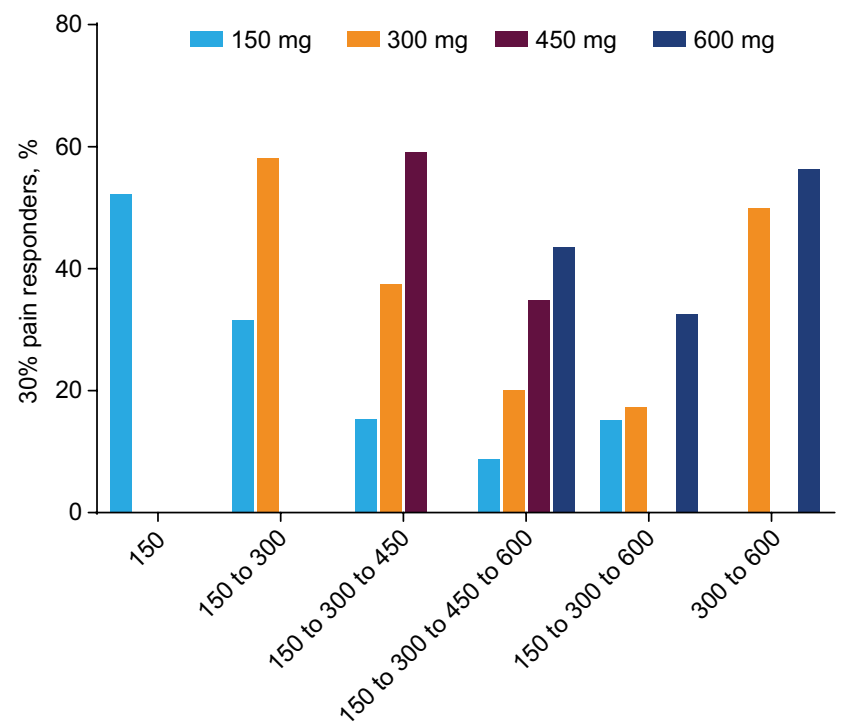

Figure I Cumulative proportion of $30 \%$ pain responders by dose for each dose pathway. Note: Cumulative percentage of patients with a $\geq 30 \%$ reduction in mean pain score from baseline at each new dose for each dose pathway group shows an increased $30 \%$ responder rate with increasing dose of pregabalin. 
showed that across every dose pathway, there was recruitment of new pain responders $(30 \%$ or $50 \%)$ at each new and higher dose of pregabalin. Table 2 shows the number (and proportion) of 30\% responders at each dose limited to only those patients who were non-responders at the previous dose in their dose pathway (i.e., non-cumulative data). For example, in the 150 to $300 \mathrm{mg} /$ day dose pathway, 100 (of 146) patients were non-responders at $150 \mathrm{mg} /$ day. When

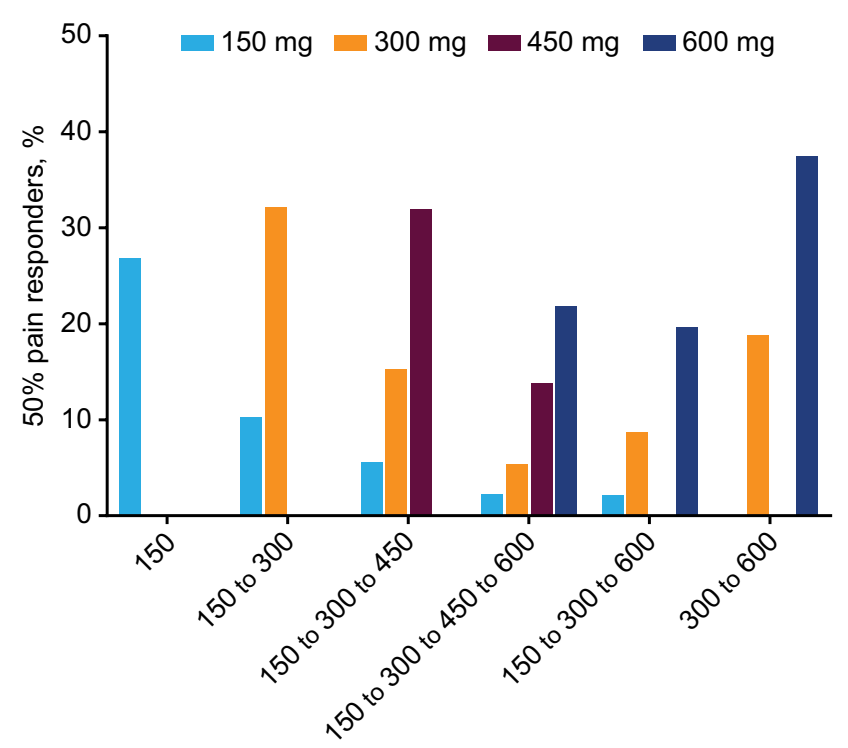

Figure 2 Cumulative proportion of $50 \%$ pain responders by dose for each dose pathway.

Note: Cumulative percentage of patients with a $\geq 50 \%$ reduction in mean pain score from baseline at each new dose for each dose pathway group shows an increased $50 \%$ responder rate with increasing dose of pregabalin. these patients were escalated to $300 \mathrm{mg}$ /day, a further 43 (of the 100 non-responding) patients were responders (Table 2). An equivalent pattern was observed with $50 \%$ responders (Table 3). These data demonstrate that for every dose pathway, previously non-responsive patients would become $30 \%$ or $50 \%$ responders with every increase in pregabalin dose.

The change in pain score from baseline for each dose pathway indicated that patients in the shorter dose pathways (i.e., those who remained on $150 \mathrm{mg} /$ day or only escalated to $300 \mathrm{mg} /$ day) had a notable larger change in pain score with pregabalin $150 \mathrm{mg} /$ day (and $300 \mathrm{mg} /$ day) than did those patients who subsequently went on to be escalated to higher doses (Table 4). This finding reflects the fact that patients with a greater response at lower doses were less likely to be escalated to a higher dose. At the same time, for those patients who were escalated to a higher dose, there was a notably greater change in pain score at each escalating dose (Table 4).

These data exclude non-compliant patients (those with $<80 \%$ compliance on pregabalin over the entire study). Considering only patients who were non-compliant for all dose pathways combined, there was a notably lower proportion of $30 \%(32.3 \%)$ and $50 \%(15.2 \%)$ responders than for treatment-compliant patients (Figures 1 and 2).

\section{Weighted estimation of change in pain score for each dose}

As assessed by MSM, higher doses of pregabalin were estimated to result in a significantly greater change in mean pain

Table 2 Thirty percent responders at each dose for each dose pathway

\begin{tabular}{|c|c|c|c|c|c|c|c|c|}
\hline \multirow[t]{2}{*}{ Dose pathway } & \multicolumn{2}{|c|}{$150 \mathrm{mg} / \mathrm{day}$} & \multicolumn{2}{|c|}{$300 \mathrm{mg} / \mathrm{day}$} & \multicolumn{2}{|c|}{$450 \mathrm{mg} / \mathrm{day}$} & \multicolumn{2}{|c|}{$600 \mathrm{mg} / \mathrm{day}$} \\
\hline & $\mathbf{N}^{\mathbf{a}}$ & $n(\%)^{b}$ & $\mathbf{N}^{\mathbf{a}}$ & n (\%) & $\mathbf{N}^{\mathbf{a}}$ & $n(\%)^{b}$ & $\mathbf{N}^{\mathbf{a}}$ & n (\%) \\
\hline \multicolumn{9}{|l|}{150 mg/day } \\
\hline Responder & 67 & $35(52.2)$ & - & & - & & - & \\
\hline Non-responder & & $32(47.8)$ & & & & & & \\
\hline \multicolumn{9}{|l|}{ I 50 to $300 \mathrm{mg} /$ day } \\
\hline Responder & 146 & $46(3 \mid .5)$ & 100 & $43(43.0)$ & - & & - & \\
\hline Non-responder & & $100(68.5)$ & & $57(57.0)$ & & & & \\
\hline \multicolumn{9}{|c|}{150 to 300 to $450 \mathrm{mg} / \mathrm{day}$} \\
\hline Responder & 144 & $22(15.3)$ & 122 & $36(29.5)$ & 86 & $31(36.1)$ & - & \\
\hline Non-responder & & $122(84.7)$ & & $86(70.5)$ & & $55(63.9)$ & & \\
\hline \multicolumn{9}{|c|}{150 to 300 to 450 to $600 \mathrm{mg} / \mathrm{day}$} \\
\hline Responder & 298 & $26(8.7)$ & 272 & $4 I(15.1)$ & 231 & $43(18.6)$ & 188 & $28(14.9)$ \\
\hline Non-responder & & $272(9 \mid .3)$ & & $231(84.9)$ & & $188(81.4)$ & & $160(85.1)$ \\
\hline \multicolumn{9}{|c|}{150 to 300 to $600 \mathrm{mg} / \mathrm{day}$} \\
\hline Responder & 46 & $7(I 5.2)$ & 39 & $3(7.7)$ & - & & 36 & $6(16.7)$ \\
\hline Non-responder & & $39(84.8)$ & & $36(92.3)$ & & & $30(83.3)$ & \\
\hline \multicolumn{9}{|l|}{300 to $600 \mathrm{mg} /$ day } \\
\hline Responder & - & & 16 & $8(50.0)$ & - & & 8 & $2(25.0)$ \\
\hline Non-responder & & & & $8(50.0)$ & & & & $6(75.0)$ \\
\hline
\end{tabular}

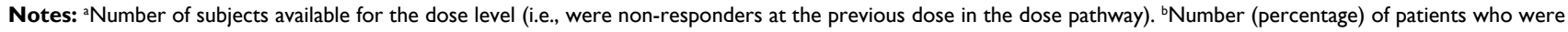
$30 \%$ responders at that dose. 
Table 3 Fifty percent responders at each dose for each dose pathway - evaluation of non-responder at low dose moving to the next dose level

\begin{tabular}{|c|c|c|c|c|c|c|c|c|}
\hline \multirow[t]{2}{*}{ Dose pathway } & \multicolumn{2}{|c|}{$150 \mathrm{mg} / \mathrm{day}$} & \multicolumn{2}{|c|}{$300 \mathrm{mg} /$ day } & \multicolumn{2}{|c|}{$450 \mathrm{mg} / \mathrm{day}$} & \multicolumn{2}{|c|}{$600 \mathrm{mg} / \mathrm{day}$} \\
\hline & $\mathbf{N}^{\mathbf{a}}$ & $n(\%)^{b}$ & $\mathbf{N}^{\mathbf{a}}$ & $\mathbf{n}(\%)^{b}$ & $\mathbf{N}^{\mathbf{a}}$ & $n(\%)^{b}$ & $\overline{\mathbf{N}^{\mathbf{a}}}$ & $n(\%)^{b}$ \\
\hline \multicolumn{9}{|l|}{$150 \mathrm{mg} / \mathrm{day}$} \\
\hline Responder & 67 & $18(26.9)$ & - & & - & & - & \\
\hline Non-responder & & $49(73.1)$ & & & & & & \\
\hline \multicolumn{9}{|l|}{150 to $300 \mathrm{mg} /$ day } \\
\hline Responder & 146 & $15(10.3)$ & $|3|$ & $32(24.4)$ & - & & - & \\
\hline Non-responder & & $|3|(89.7)$ & & $99(75.6)$ & & & & \\
\hline \multicolumn{9}{|c|}{150 to 300 to $450 \mathrm{mg} / \mathrm{day}$} \\
\hline Responder & 144 & $8(5.6)$ & 136 & $18(13.2)$ & 118 & $21(17.8)$ & - & \\
\hline Non-responder & & $136(94.4)$ & & I I 8 (86.8) & & $97(82.2)$ & & \\
\hline \multicolumn{9}{|c|}{150 to 300 to 450 to $600 \mathrm{mg} / \mathrm{day}$} \\
\hline Responder & 298 & $8(2.7)$ & 290 & $13(4.5)$ & 277 & $25(9.0)$ & 252 & $29(11.5)$ \\
\hline Non-responder & & $290(97.3)$ & & $277(95.5)$ & & $252(91.0)$ & & $223(88.5)$ \\
\hline \multicolumn{9}{|c|}{150 to 300 to $600 \mathrm{mg} / \mathrm{day}$} \\
\hline Responder & 46 & $\mathrm{I}(2.2)$ & 45 & $4(8.9)$ & - & & 41 & $5(12.2)$ \\
\hline Non-responder & & $45(97.8)$ & & $4 I(9 I . I)$ & & & $36(87.8)$ & \\
\hline \multicolumn{9}{|c|}{300 to $600 \mathrm{mg} /$ day } \\
\hline Responder & - & & 16 & $3(18.7)$ & - & & 13 & $3(23.1)$ \\
\hline Non-responder & & & & $13(81.3)$ & & & & $10(76.9)$ \\
\hline
\end{tabular}

Notes: aNumber of subjects available for the dose level (i.e., were non-responders at the previous dose in the dose pathway). ${ }^{b}$ Number (percentage) of patients who were $50 \%$ responders at that dose.

Table 4 Mean change in pain score from baseline for each dose pathway - evaluation of non-responder at low dose moving to the next dose level

\begin{tabular}{|c|c|c|c|c|c|c|c|c|c|c|c|c|}
\hline \multirow[t]{2}{*}{ Dose } & \multicolumn{2}{|c|}{$150 \mathrm{mg} / \mathrm{day}$} & \multicolumn{2}{|c|}{$\begin{array}{l}150 \text { to } 300 \\
\mathrm{mg} / \text { day }\end{array}$} & \multicolumn{2}{|c|}{$\begin{array}{l}150 \text { to } 300 \text { to } \\
450 \mathrm{mg} / \text { day }\end{array}$} & \multicolumn{2}{|c|}{$\begin{array}{l}150 \text { to } 300 \text { to } 450 \\
\text { to } 600 \mathrm{mg} / \text { day }\end{array}$} & \multicolumn{2}{|c|}{$\begin{array}{l}150 \text { to } 300 \text { to } \\
600 \mathrm{mg} / \text { day }\end{array}$} & \multicolumn{2}{|c|}{$\begin{array}{l}300 \text { to } 600 \\
\mathrm{mg} / \text { day }\end{array}$} \\
\hline & $\mathbf{n}^{\mathbf{a}}$ & Change $^{\mathrm{b}}$ & $\mathbf{n}^{\mathbf{a}}$ & Change $^{\mathrm{b}}$ & $\mathbf{n}^{\mathbf{a}}$ & Change $^{\mathrm{b}}$ & $\mathbf{n}^{\mathbf{a}}$ & Change $^{\mathrm{b}}$ & $\mathbf{n}^{\mathbf{a}}$ & Change $^{\mathrm{b}}$ & $\mathbf{n}^{\mathbf{a}}$ & Change \\
\hline \multicolumn{13}{|c|}{ Based on $30 \%$ pain responders population } \\
\hline $150 \mathrm{mg} /$ day & 67 & -1.92 & 146 & -1.33 & 144 & -0.72 & 298 & -0.55 & 46 & -0.50 & & \\
\hline $300 \mathrm{mg} /$ day & & & 100 & -1.56 & 122 & -1.18 & 272 & -0.86 & 39 & -0.46 & 16 & -2.19 \\
\hline $450 \mathrm{mg} /$ day & & & & & 86 & -1.34 & 231 & -1.02 & & & & \\
\hline $600 \mathrm{mg} /$ day & & & & & & & 188 & -0.97 & 36 & -0.62 & 8 & -1.90 \\
\hline \multicolumn{13}{|c|}{ Based on $50 \%$ pain responders population } \\
\hline 150 mg/day & 67 & -1.92 & 146 & -1.33 & 144 & -0.72 & 298 & -0.55 & 46 & -0.50 & & \\
\hline $300 \mathrm{mg} /$ day & & & $|3|$ & -2.00 & 136 & -1.32 & 290 & -0.98 & 45 & -0.77 & 16 & -2.19 \\
\hline $450 \mathrm{mg} /$ day & & & & & 118 & -1.79 & 277 & -1.35 & & & & \\
\hline $600 \mathrm{mg} /$ day & & & & & & & 252 & -1.50 & 41 & -1.02 & 13 & -2.45 \\
\hline
\end{tabular}

Notes: ${ }^{\mathrm{N} N u m b e r}$ of subjects available for the next dose level (i.e., were non-responders at the previous dose in the dose pathway). ${ }^{\mathrm{b}} \mathrm{Change}$ in mean pain score from baseline based on the number of subjects available at that dose level.

score at each week of assessment (Figure 3). Restricting the analysis to only those patients with $\geq 80 \%$ compliance with pregabalin resulted in similar results (not shown). This was also supported by a comparison of the weighted MSM analysis with an unweighted estimate of the change in mean pain score, with each analysis showing similar results (not shown).

Direct comparison of the MSM-estimated change with flexible-dose pregabalin with the estimated change in mean pain score from baseline with data from fixed-dose clinical trials of pregabalin (a total of 3128 patients; 516 receiving pregabalin $150 \mathrm{mg} /$ day, 1679 receiving pregabalin
$300 \mathrm{mg} /$ day, and 933 receiving pregabalin $600 \mathrm{mg} /$ day) demonstrated a similar dose-response pattern for each dose of pregabalin (Figure 4).

\section{Discussion}

Pregabalin is recommended as a treatment for diverse neuropathic pain conditions ${ }^{4,8-10}$ where it is advised that it be carefully escalated to the optimal dose. ${ }^{4,6,15}$ In the USA, the maximum approved dose of pregabalin is $300 \mathrm{mg}$ /day for DPN and $600 \mathrm{mg}$ /day for PHN, ${ }^{6}$ while in Europe it is 600 $\mathrm{mg}$ /day for all neuropathic pain. ${ }^{45}$ Despite this, many patients 


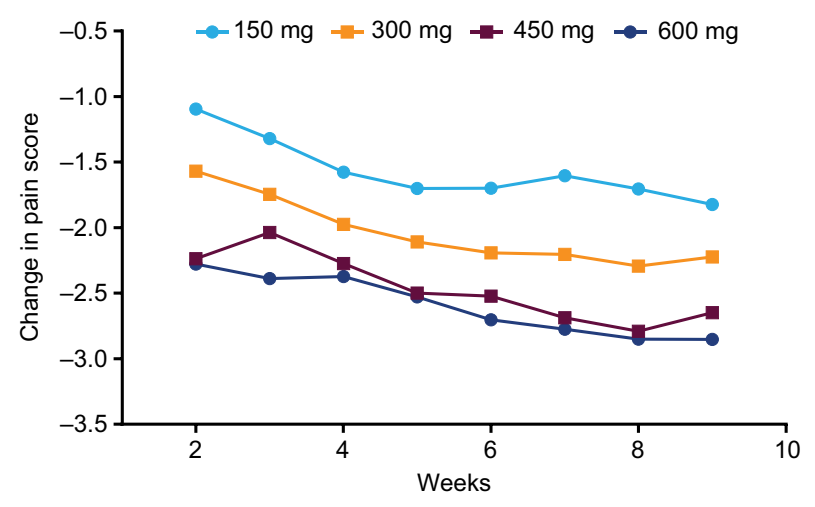

Figure 3 Estimated change in pain score from baseline by marginal structural model showing that increasing doses of pregabalin result in a greater reduction in pain score.

Notes: All doses of pregabalin significantly $(P<0.05)$ improved pain score versus I50 $\mathrm{mg}$ at each week with the exception of week 9 for $150 \mathrm{mg} /$ day versus $300 \mathrm{mg} /$ day. Change in pain score with pregabalin $450 \mathrm{mg} /$ day and $600 \mathrm{mg} /$ day was significantly $>300 \mathrm{mg} /$ day at each week. There was no significant difference observed between $450 \mathrm{mg} /$ day and $600 \mathrm{mg} /$ day at any week.

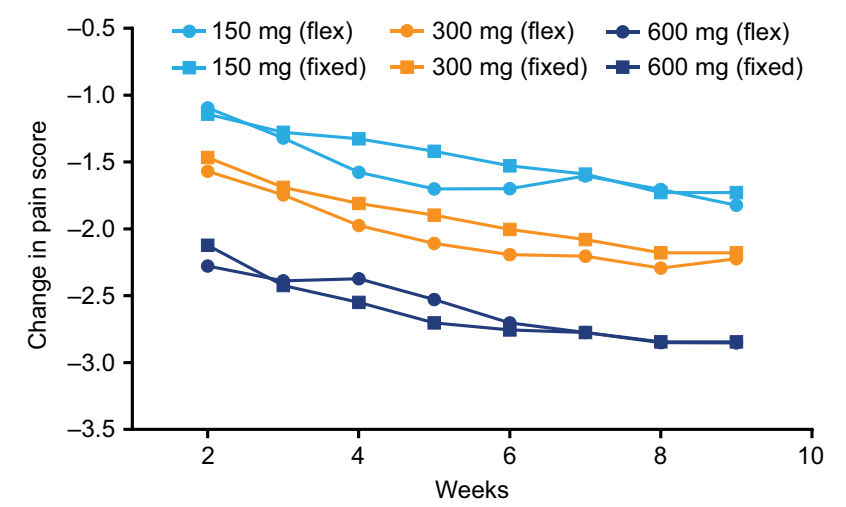

Figure 4 Dose response in flexible-dose studies of pregabalin is similar to that observed in fixed-dose studies.

Notes: Marginal structural model-estimated change in mean pain score from baseline for flexible-dose pregabalin (flex) and estimated change in mean pain score from baseline for fixed-dose pregabalin (fixed). Data shown by week for each dose.

may not receive the most effective dose of pregabalin, with a recent drug utilization study in the UK indicating that the approximate median prescribed dose of pregabalin for neuropathic pain was only $150 \mathrm{mg} /$ day. ${ }^{16}$ This analysis provides evidence that new patients will tend to respond with every increase in pregabalin dose.

Neuropathic pain can be challenging to treat effectively. ${ }^{2}$ While there are a number of treatment options, not all are effective in all patients. For instance, data on the efficacy of pregabalin in patients with lower back pain are inconsistent. ${ }^{46,47}$ In a randomized withdrawal trial, pregabalin was not shown to be effective in patients with chronic lumbosacral radiculopathy. ${ }^{48}$ Even for those conditions where its efficacy is well established, many patients will not respond to treatment with pregabalin. ${ }^{11}$ As physicians are advised to ensure that effective and tolerable treatment for neuropathic pain is initiated as soon as possible, ${ }^{2}$ it is important to ascertain quickly if a treatment is ineffective so that other options can be tested. In these circumstances, it may be understandable why the time is not taken to escalate some patients to a higher, efficacious dose of pregabalin. However, of the 701 patients in this analysis who took the $150 \mathrm{mg}$ /day dosing, 136 (19.4\%) responded at that dose. Of those who continued to higher doses, 231 (33.0\%) responded at a higher dose. These data do not correct for the tendency for higher doses to be used when patients have inadequate response at a lower dose. The MSM analyses make some correction for this tendency in dose escalation and indicate that it can be worthwhile to persist with pregabalin until the dose that delivers optimal analgesia and tolerable side effects is utilized.

Physicians may be reluctant to escalate the dose of pregabalin due to concerns about adverse events. A previous analysis described the incidence of common adverse events with each dose of pregabalin. ${ }^{49}$ In that analysis, the incidence of most adverse events was higher with higher fixed doses (450 or $600 \mathrm{mg} /$ day) of pregabalin. ${ }^{49}$ However, the incidence of adverse events with flexible-dose pregabalin was lower than with any fixed dose $>150 \mathrm{mg} /$ day. ${ }^{49}$ In addition, most adverse events emerged soon after the start of treatment and resolved within 1-2 weeks. ${ }^{49}$ It was advised that potential adverse events with pregabalin be discussed with patients, before and during treatment, as greater awareness of what to expect could help manage expectations. ${ }^{49}$ Together with the data reported here, this suggests that communication and careful dose titration could result in improved pain outcomes for patients.

Fixed dose studies have previously demonstrated a clear dose response with pregabalin. ${ }^{11,13}$ In these studies, patients were assigned to a specific fixed dose prior to treatment with the dose response being shown for a population of patients. Here, for the first time, this analysis shows that this dose response also exists for flexible-dose pregabalin, with individual patients being shown to respond to increasing doses. This dose response was shown to be broadly equivalent in the direct comparison between flexible- and fixed-dose pregabalin shown in Figure 4. This may suggest that in the future, some initial fixed-dose clinical trials could theoretically be replaced with flexible-dosing trials that would allow for fewer treatment arms. However, this would require additional data, and confirmation with other treatments and in other patient groups before it could be considered. While a previous analysis also used a MSM to evaluate dose-response in inflexible-dose trials of an antipsychotic, the analysis did not directly compare this 
with data from fixed-dose trials. ${ }^{50}$ We are not aware of any comparable analysis for any treatment for neurological pain.

\section{Limitation}

The descriptive part of this analysis was limited to those patients who were $\geq 80 \%$ compliant with treatment. As would be expected, there was a notably lower rate of efficacy among those patients who were $<80 \%$ compliant. As these patients could not be considered representative of patients treated with the designated dose, they were excluded from the analysis. As a result, the proportion of patients responding at each dose in this analysis may be overstated relative to the full population. This could be considered a limitation of this analysis as in routine clinical practice it is likely that many patients would be $<80 \%$ compliant with treatment, emphasizing the importance of promoting treatment compliance in clinical practice. Nevertheless, the MSM analysis was conducted in both those patients who were $\geq 80 \%$ compliant and in all patients together. The data for all patients are presented here (Figures 3 and 4) but the results when considering compliant patients only were equivalent.

\section{Conclusion}

The analysis demonstrates that many patients who do not respond to pregabalin at lower doses will subsequently respond when the dose is increased. Physicians are advised to follow treatment guidelines and escalate pregabalin to the dose that delivers optimal analgesia and tolerable side effects.

\section{Acknowledgments}

This study was sponsored by Pfizer. Michael Serpell has received honoraria from Astellas, Grünenthal, NAPP, and Pfizer for speaking at meetings. His institution has received research support in the past 5 years from commercial studies sponsored by Astellas, Grünenthal, and NAPP. Medical writing support was provided by Joshua Fink, PhD, of Engage Scientific Solutions, and funded by Pfizer.

\section{Disclosure}

Mark Latymer, Mary Almas, Marie Ortiz, Bruce Parsons, and Rita Prieto are employees of Pfizer and hold stock options with Pfizer. The authors report no other conflicts of interest in this work.

\section{References}

1. Treede RD, Jensen TS, Campbell JN, et al. Neuropathic pain: redefinition and a grading system for clinical and research purposes. Neurology. 2008;70(18):1630-1635.
2. Smith BH, Lee J, Price C, Baranowski AP. Neuropathic pain: a pathway for care developed by the British Pain Society. Br J Anaesth. 2013;111(1):73-79.

3. Berger A, Dukes EM, Oster G. Clinical characteristics and economic costs of patients with painful neuropathic disorders. $J$ Pain. 2004;5(3):143-149.

4. Attal N, Cruccu G, Baron R, et al. EFNS guidelines on the pharmacological treatment of neuropathic pain: 2010 revision. Eur J Neurol. 2010;17(9):e1113-e1188.

5. Torrance N, Ferguson JA, Afolabi E, et al. Neuropathic pain in the community: more under-treated than refractory? Pain. 2013;154(5):690-699.

6. Pfizer Inc. LYRICA prescribing information. Availablefrom: http://www. pfizer.com/files/products/uspi_lyrica.pdf. Accessed July 23, 2016.

7. Lyrica ${ }^{\circledR}$ Summary of Product Characteristics. Sandwich, UK: Pfizer Ltd. Available from: http://www.ema.europa.eu/docs/en_GB/document_ library/EPAR___Product_Information/human/000546/WC500046602. pdf. Accessed July 23, 2016.

8. O'Connor AB, Dworkin RH. Treatment of neuropathic pain: an overview of recent guidelines. Am J Med. 2009;122(10 Suppl):S22-S32.

9. Bril V, England J, Franklin GM, et al. Evidence-based guideline: treatment of painful diabetic neuropathy: report of the American Academy of Neurology, the American Association of Neuromuscular and Electrodiagnostic Medicine, and the American Academy of Physical Medicine and Rehabilitation. Neurology. 2011;76(20):1758-1765.

10. Dubinsky RM, Kabbani H, El-Chami Z, Boutwell C, Ali H; Quality Standards Subcommittee of the American Academy of Neurology. Practice parameter: treatment of postherpetic neuralgia: an evidencebased report of the Quality Standards Subcommittee of the American Academy of Neurology. Neurology. 2004;63(6):959-965.

11. Moore RA, Straube S, Wiffen PJ, Derry S, McQuay HJ. Pregabalin for acute and chronic pain in adults. Cochrane Database Syst Rev. 2009(3):CD007076.

12. IMS MIDAS data from quarter ending June 2004 till quarter ending September 2016. Average daily dose based on IMS MIDAS data Q3 2016. Data on file.

13. Snedecor SJ, Sudharshan L, Cappelleri JC, Sadosky A, Mehta S, Botteman M. Systematic review and meta-analysis of pharmacological therapies for painful diabetic peripheral neuropathy. Pain Pract. 2014;14(2):167-184.

14. Juhn MS, Parsons B, Varvara R, Sadosky A. Pregabalin for painful diabetic peripheral neuropathy: strategies for dosing, monotherapy versus combination therapy, treatment-refractory patients, and adverse events. Curr Med Res Opin. 2015;31(5):1017-1026.

15. Freeman R, Durso-Decruz E, Emir B. Efficacy, safety, and tolerability of pregabalin treatment for painful diabetic peripheral neuropathy: findings from seven randomized, controlled trials across a range of doses. Diabetes Care. 2008;31(7):1448-1454.

16. Asomaning K, Abramsky S, Liu Q, Zhou X, Sobel RE, Watt S. Pregabalin prescriptions in the United Kingdom: a drug utilisation study of The Health Improvement Network (THIN) primary care database. Int J Clin Pract. 2016;70(5):380-388.

17. Freeman R, Emir B, Parsons B. Predictors of placebo response in peripheral neuropathic pain: insights from pregabalin clinical trials. J Pain Res. 2015;8:257-268.

18. Stacey BR, Barrett JA, Whalen E, Phillips KF, Rowbotham MC. Pregabalin for postherpetic neuralgia: placebo-controlled trial of fixed and flexible dosing regimens on allodynia and time to onset of pain relief. J Pain. 2008;9(11):1006-1017.

19. Freynhagen R, Strojek K, Griesing T, Whalen E, Balkenohl M. Efficacy of pregabalin in neuropathic pain evaluated in a 12-week, randomised, double-blind, multicentre, placebo-controlled trial of flexible- and fixed-dose regimens. Pain. 2005;115(3):254-263.

20. Guan Y, Ding X, Cheng Y, et al. Efficacy of pregabalin for peripheral neuropathic pain: results of an 8-week, flexible-dose, doubleblind, placebo-controlled study conducted in China. Clin Ther. 2011;33(2):159-166. 
21. van Seventer R, Bach FW, Toth CC, et al. Pregabalin in the treatment of post-traumatic peripheral neuropathic pain: a randomized double-blind trial. Eur J Neurol. 2010;17(8):1082-1089.

22. Moon DE, Lee DI, Lee SC, et al. Efficacy and tolerability of pregabalin using a flexible, optimized dose schedule in Korean patients with peripheral neuropathic pain: a 10-week, randomized, double-blind, placebocontrolled, multicenter study. Clin Ther. 2010;32(14):2370-2385.

23. Richter RW, Portenoy R, Sharma U, Lamoreaux L, Bockbrader H, Knapp LE. Relief of painful diabetic peripheral neuropathy with pregabalin: a randomized, placebo-controlled trial. J Pain. 2005;6(4):253-260.

24. Lesser H, Sharma U, LaMoreaux L, Poole RM. Pregabalin relieves symptoms of painful diabetic neuropathy: a randomized controlled trial. Neurology. 2004;63(11):2104-2110.

25. Sharma U, Griesing T, Emir B, Young JP Jr. Time to onset of neuropathic pain reduction: a retrospective analysis of data from nine controlled trials of pregabalin for painful diabetic peripheral neuropathy and postherpetic neuralgia. Am J Ther. 2010;17(6):577-585.

26. Sabatowski R, Galvez R, Cherry DA, et al. Pregabalin reduces pain and improves sleep and mood disturbances in patients with post-herpetic neuralgia: results of a randomised, placebo-controlled clinical trial. Pain. 2004;109(1-2):26-35.

27. Siddall PJ, Cousins MJ, Otte A, Griesing T, Chambers R, Murphy TK. Pregabalin in central neuropathic pain associated with spinal cord injury: a placebo-controlled trial. Neurology. 2006;67(10):1792-1800.

28. Dworkin RH, Corbin AE, Young JP Jr, et al. Pregabalin for the treatment of postherpetic neuralgia: a randomized, placebo-controlled trial. Neurology. 2003;60(8):1274-1283.

29. Rosenstock J, Tuchman M, LaMoreaux L, Sharma U. Pregabalin for the treatment of painful diabetic peripheral neuropathy: a double-blind, placebo-controlled trial. Pain. 2004;110(3):628-638

30. Tolle T, Freynhagen R, Versavel M, Trostmann U, Young JP Jr. Pregabalin for relief of neuropathic pain associated with diabetic neuropathy: a randomized, double-blind study. Eur J Pain. 2008;12(2): 203-213.

31. van Seventer R, Feister HA, Young JP Jr, Stoker M, Versavel M, Rigaudy L. Efficacy and tolerability of twice-daily pregabalin for treating pain and related sleep interference in postherpetic neuralgia: a 13-week, randomized trial. Curr Med Res Opin. 2006;22(2): 375-384.

32. Arezzo JC, Rosenstock J, Lamoreaux L, Pauer L. Efficacy and safety of pregabalin $600 \mathrm{mg} / \mathrm{d}$ for treating painful diabetic peripheral neuropathy: a double-blind placebo-controlled trial. BMC Neurol. 2008;8:33.

33. Simpson DM, Schifitto G, Clifford DB, et al; 1066 HIV Neuropathy Study Group. Pregabalin for painful HIV neuropathy: a randomized, double-blind, placebo-controlled trial. Neurology. 2010;74(5):413-420.

34. Cardenas DD, Nieshoff EC, Suda K, et al. A randomized trial of pregabalin in patients with neuropathic pain due to spinal cord injury. Neurology. 2013;80(6):533-539.

35. Ogawa S, Suzuki M, Arakawa A, Araki S, Yoshiyama T. Efficacy and tolerability of pregabalin for postherpetic neuralgia: a multicenter, randomized, double-blind, placebo-controlled clinical trial. J Japan Soc Pain Clin. 2010;17(2):141-152.
36. Satoh J, Yagihashi S, Baba M, et al. Efficacy and safety of pregabalin for treating neuropathic pain associated with diabetic peripheral neuropathy: a 14 week, randomized, double-blind, placebo-controlled trial. Diabet Med. 2011;28(1):109-116.

37. Simpson DM, Rice AS, Emir B, et al. A randomized, double-blind, placebo-controlled trial and open-label extension study to evaluate the efficacy and safety of pregabalin in the treatment of neuropathic pain associated with human immunodeficiency virus neuropathy. Pain. 2014;155(10):1943-1954.

38. Raskin P, Huffman C, Yurkewicz L, et al. Pregabalin in Subjects With Painful Diabetic Peripheral Neuropathy Using an NSAID for Other Pain Conditions: A Double-Blind Crossover Study. Clin J Pain. 2016;32(3):203-210.

39. Huffman C, Stacey BR, Tuchman M, et al. Efficacy and Safety of Pregabalin in the Treatment of Patients With Painful Diabetic Peripheral Neuropathy and Pain on Walking. Clin J Pain. 2015;31(11):946-958.

40.Liu Q, Chen H, Xi L, et al. A randomized, double-blind placebo-controlled trial to evaluate the efficacy and safety of pregabalin for postherpetic neuralgia in a population of Chinese patients. Pain Pract. 2017;17(1):62-69.

41. Farrar JT, Young JP Jr, LaMoreaux L, Werth JL, Poole RM. Clinical importance of changes in chronic pain intensity measured on an 11-point numerical pain rating scale. Pain. 2001;94(2):149-158.

42. Dworkin RH, Turk DC, Farrar JT, et al. Core outcome measures for chronic pain clinical trials: IMMPACT recommendations. Pain. 2005;113(1-2):9-19.

43. Faries DE, Kadziola ZA. Analysis of longitudinal observational data using marginal structural models. In: Faries DE, Leon AC, Haro JM, et al, editors. Analysis of Observational Health Care Data Using SAS. Cary, NC: SAS Institute Inc. 2010: 211-230.

44. Hernan MA, Brumback B, Robins JM. Marginal structural models to estimate the causal effect of zidovudine on the survival of HIV-positive men. Epidemiology. 2000;11(5):561-570.

45. Pfizer Ltd. Lyrica ${ }^{\circledR}$ Summary of Product Characteristics. Available from: http://www.ema.europa.eu/docs/en_GB/document_library/ EPAR_-_Product_Information/human/000546/WC500046602.pdf. Accessed July 23, 2016

46. Baron R, Binder A, Attal N, Casale R, Dickenson AH, Treede RD. Neuropathic low back pain in clinical practice. Eur J Pain. 2016;20(6): 861-873.

47. Taguchi T, Igarashi A, Watt S, et al. Effectiveness of pregabalin for the treatment of chronic low back pain with accompanying lower limb pain (neuropathic component): a non-interventional study in Japan. J Pain Res. 2015;8:487-497.

48. Baron R, Freynhagen R, Tolle TR, et al. The efficacy and safety of pregabalin in the treatment of neuropathic pain associated with chronic lumbosacral radiculopathy. Pain. 2010;150(3):420-427.

49. Freynhagen R, Serpell M, Emir B, et al. A comprehensive drug safety evaluation of pregabalin in peripheral neuropathic pain. Pain Pract. 2015;15(1):47-57.

50. Lipkovich I, Adams DH, Mallinckrodt C, Faries D, Baron D, Houston JP. Evaluating dose response from flexible dose clinical trials. BMC Psychiatry. 2008;8:3.
Journal of Pain Research

\section{Publish your work in this journal}

The Journal of Pain Research is an international, peer reviewed, open access, online journal that welcomes laboratory and clinical findings in the fields of pain research and the prevention and management of pain. Original research, reviews, symposium reports, hypothesis formation and commentaries are all considered for publication.

\section{Dovepress}

The manuscript management system is completely online and includes a very quick and fair peer-review system, which is all easy to use. Visit http://www.dovepress.com/testimonials.php to read real quotes from published authors. 